\title{
O INTÉRPRETE DE LIBRAS NO CONTEXTO DA PÓS- GRADUAÇÃO: UM OLHAR PARA O GÊNERO DO DISCURSO
}

\author{
Vânia de Aquino Albres Santiago $\mathbf{1}^{\mathbf{1}}$ \\ 1Pontifícia Universidade Católica de São Paulo, São Paulo, São Paulo, Brasil \\ Cristina Broglia Feitosa de Lacerda ${ }^{2}$ \\ ${ }^{2}$ Universidade Federal de São Carlos, São Carlos, São Paulo, Brasil
}

\begin{abstract}
Resumo: Nosso objetivo é analisar a interpretação de língua de sinais na esfera educacional, no contexto da pós-graduação lato sensu, focalizando as especificidades do gênero do discurso. Assim, apresentamos como questões de pesquisa: Com quais gêneros discursivos têm que lidar os intérpretes educacionais na pós-graduação? Quais as estratégias dos intérpretes nesse contexto? Seguindo no pensamento bakhtiniano e do Círculo ${ }^{1}$, nas reflexões e estudos sobre o intérprete educacional, concebemos a interpretação como um processo discursivo, no qual a atuação dos intérpretes com os alunos depende do contexto em que estão inseridos. Consideramos que a atuação dos intérpretes educacionais é regida pelas coerções do gênero e, portanto, as decisões tradutórias, estilo de linguagem, modalidades de interpretação e formas de interação dizem respeito ao contexto específico em que atuam.
\end{abstract}

Palavras-chave: Interpretação educacional; Libras; Gêneros do discurso; Pós-graduação

${ }^{1}$ O Círculo de Bakhtin foi um grupo de filósofos, estudiosos da linguagem e artistas russos inauguraram uma filosofia da linguagem que leva em consideração diferentes elementos situados nas dimensões semiótico e ideológicas da linguagem. Para o pensamento bakhtiniano a linguagem tem natureza ideológica, justamente porque reflete e refrata os valores sociais daqueles que a põem em funcionamento. Os principais autores do Círculo são Mikhail Bakhtin, Pável Medviédev e Valentín Volóchinov. 


\title{
LIBRAS INTERPRETER IN THE POST-GRADUATION CONTEXT: A LOOK AT THE GENRE OF DISCOURSE
}

\begin{abstract}
Our objective is to analyze the interpretation of sign language in the educational sphere, in the context of post-graduation lato sensu, focusing on the specificities of the genre of discourse. Thus, we present as research questions: What characteristics of the discursive genre emerge in the performance of the Educational Interpreter? What statements reveal and characterize the genre of discourse in graduate studies based on the performance of the interpreter? Following Bakhtinian and Circle thinking, reflections and studies on the educational interpreter, we conceive of interpretation as a discursive process, in which the performance of interpreters with students depends on the context in which they are inserted. We consider that the performance of educational interpreters is governed by genre's coercions and, therefore, translation decisions, language style, modes of interpretation and forms of interaction are related to the specific context in which they operate.
\end{abstract}

Keywords: Educational interpretation; Libras; Genre of discourse; Higher education

\section{Introdução}

O objetivo desse artigo é analisar a interpretação de língua de sinais no contexto da pós-graduação lato sensu, focalizando as coerções e especificidades dos gêneros do discurso que circulam nesse contexto. Assim, apresentamos como questões de pesquisa: Com quais gêneros discursivos têm que lidar os intérpretes educacionais na pós-graduação? Quais as estratégias dos intérpretes nesse contexto?

No processo de interpretação intralinguística o intérprete toma para si uma enunciação que não é propriamente sua, mas que ideologicamente transpassa sua realidade de uso da linguagem e estrutura sócio-ideológica. No processo de interpretação, a palavra dita em uma língua deve ser enunciada em outra língua, processo que envolve ativamente a consciência do indivíduo que toma o papel de mediador e mobilizador de discursos. Tais aspectos são fortemente

Cad. Trad., Florianópolis, v. 41, $\mathbf{n}^{0}$ esp. 2, p. 107-127, ago/dez, 2021.108 
influenciados pelo contexto e, mais especificamente, pelo gênero discursivo circulante no ato da interpretação.

$\mathrm{O}$ atual discurso sobre o Tradutor e Intérprete de Língua de Sinais (TILS) e sobre os processos de mediação educacional indicam que sua formação deve ser pensada com certa urgência, já que paira uma discussão sobre a formação para determinados e específicos campos de atuação. Para pensar essa formação é essencial a investigação científica e metodológica da atuação dos tradutores e intérpretes de língua de sinais para identificar em que contextos trabalham e com quais campos de conhecimento têm que lidar.

Pretendemos contribuir com reflexões acerca da atividade do TILS, a partir da necessidade gerada pela inclusão educacional em consonância com a proposta de educação bilíngue, na presença de intérprete em sala de aula, neste artigo, com olhar para a pós-graduação. Decorrente de pesquisa anterior (Santiago 1-97; Santiago e Lacerda), defendemos que o conhecimento das especificidades de cada nível de ensino é fundamental para que os Intérpretes Educacionais (IE) possam refletir sobre sua prática. Partindo dessa preocupação, justifica-se a especial atenção para a atuação de TILS na pós-graduação.

\section{Os gêneros do discurso}

No pensamento bakhtiniano e do Círculo, a questão do gênero do discurso está diretamente ligada ao conceito de enunciado, tanto no que diz respeito ao ato de produção do discurso oral, quanto para o discurso escrito. Segundo os estudos bakhtinianos, os enunciados têm como unidades da comunicação discursiva peculiaridades estruturais comuns e limites precisos, assim, para estudo de um gênero, faz-se necessária a compreensão desses limites, para além do conteúdo temático, da construção composicional e de outros aspectos, o estilo é especialmente determinante (Albres e Santiago).

Tomamos, aqui, o conceito bakhtiniano de gênero do discurso, resultado das diversas confluências, imbricações discursivas, ideolo-

Cad. Trad., Florianópolis, v. 41, $\mathrm{n}^{0}$ esp. 2, p. 107-127, ago/dez, 2021. 109 
gicamente envolvidas, em que nos constituímos como seres humanos, pensantes e produtivos. Nas palavras de Bakhtin "O conteúdo temático, o estilo, a construção composicional - estão indissoluvelmente ligados no conjunto de enunciados e são intimamente determinados pela especificidade de campo da comunicação" (Bakhtin 12).

Para Bakhtin, onde há estilo há gênero e a passagem do estilo de um gênero para outro não só modifica o caráter do estilo nas condições do gênero que não lhe é próprio, como também destrói ou renova tal gênero. Assim, para o autor, os enunciados e seus tipos são correias de transmissão entre a história da sociedade e a história da linguagem (Bakhtin).

\begin{abstract}
A relação orgânica e indissolúvel do estilo com o gênero se revela nitidamente também na questão dos estilos de linguagem ou funcionais]... [ [que] não são outra coisa senão estilos de gênero de determinadas esferas da atividade humana e da comunicação (Bakhtin 18).
\end{abstract}

Outro aspecto constitutivo dos enunciados, e, portanto, dos gêneros do discurso, para o autor é a possibilidade de direcionamento do enunciado a alguém, a possibilidade de endereçamento. "Todas essas modalidades e concepções do destinatário são determinadas pelo campo da atividade humana e da vida a qual tal enunciado se refere" (Bakhtin 63). Esse aspecto do direcionamento dos enunciados evidencia, na análise dos gêneros, as relações hierárquicas entre os falantes e as coerções advindas dessas relações.

Para caracterização dos gêneros do discurso, e, consequentemente, para sua leitura, há que se considerar a peculiaridade de conclusibilidade dos enunciados que compõe o gênero, que para Bakhtin, "é uma espécie de aspecto interno da alternância dos sujeitos do discurso" (Bakhtin 35). Ainda sobre a conclusibilidade dos enunciados, observamos como importante critério a possibilidade de resposta a um determinado enunciado, em um dado momento e em determinadas condições.

Cad. Trad., Florianópolis, v. 41, $\mathrm{n}^{0}$ esp. 2, p. 107-127, ago/dez, 2021. 110 
O estilo indissociável de determinadas unidades temáticas e o que é de especial importância - de determinadas unidades composicionais: determinados tipos de construção do conjunto, do seu acabamento, depois da relação do falante com outros participantes da comunicação discursiva - com os ouvintes, os leitores, os parceiros, o discurso do outro, etc. (Bakhtin 18)

Todos os aspectos mencionados: estilo, composição, alternância dos falantes, endereçamento/direcionamento e conteúdo, são ponto de partida para o estudo dos gêneros, mas, segundo Bakhtin, qualquer análise parte do processo real de vida e ecos ideológicos deste processo analisado considerando-se o contexto sócio-histórico onde os enunciados estão situados.

\section{O intérprete educacional}

Nas reflexões e estudos sobre o IE, concebemos a interpretação como um processo discursivo, no qual, a atuação dos intérpretes com os alunos depende do contexto em que estão inseridos. O IE está embebido de pensamentos influenciados pelo contexto social da inclusão, das dificuldades que enfrenta diariamente, do discurso do professor, do discurso dos surdos, da necessidade de respeito à diferença linguística, entre outros (Mendes). Assim, consideramos a interpretação educacional como campo de significações e sentidos que envolve concepções do IE sobre tudo que o rodeia, sobre o contexto em que está inserido e, principalmente, sobre as concepções acerca da surdez e sobre o surdo para quem interpreta em aula.

Sobral argumenta que para além do texto, a atividade de tradução revela que o discurso é a unidade com que se trabalha. Para ele, o texto é uma materialidade em que só são criados sentidos a partir da discursivização, do uso dos textos por sujeitos em uma situação concreta, sendo então o discurso uma unidade de produção de sentidos, realizados por, para e entre sujeitos. A perspectiva dia-

Cad. Trad., Florianópolis, v. 41, $\mathbf{n}^{0}$ esp. 2, p. 107-127, ago/dez, 2021. 111 
lógica, a produção de sentidos no espaço de sala de aula é marcada pela intersubjetividade, pelas relações de alteridade e de poder das interações. Sobral explica que o sujeito da linguagem, do discurso é um agente, um "inter-agente" que age na "presença" de outrem, para ele os enunciados/discursos são considerados um produto desse processo interativo e dialógico. Afirma ainda que a produção de sentido representa um processo permanente de negociação, que está sempre se formando, se alterando, ressurgindo, etc.

Nascimento assume a tradução/interpretação como um ato enunciativo discursivo a partir da perspectiva dialógica de estudo da linguagem, significando a materialidade produzida nesse ato como um enunciado concreto, concebido como unidade real da constante cadeia de comunicação discursiva. O TILS, como enunciador/mediador em uma interação também seleciona os recursos linguísticos mais adequados para conduzir o discurso da língua fonte para a língua alvo a partir de um espaço-tempo específico, sua tradução/ interpretação não se estagna no nível linguístico, caso contrário sua atuação seria limitada aos componentes abstratos e busca de correspondentes linguísticos e terminológicos. Portanto, o tradutor/intérprete sendo enunciador, produtor de discursos, a partir da intersubjetividade das interações mobiliza, não apenas componentes linguísticos, mas discursos, pois, "todo enunciado está inserido em um tipo de esfera da atividade humana e ele, o enunciado, se referirá à esfera pela qual foi produzido" (Nascimento 51).

Brait, sobre os estudos do Círculo de Bakhtin, infere sobre o nascimento de uma análise/teoria dialógica do discurso e explica seu embasamento constitutivo: a indissolúvel relação entre línguas, linguagens, história e sujeitos que instaura os estudos da linguagem. Circunscritos a uma concepção de linguagem, de construção e produção de sentidos necessariamente apoiadas nas relações discursivas empreendidas por sujeitos historicamente situados, em cada esfera discursiva.

$\mathrm{Na}$ esfera do discurso, educação de surdos no contexto da inclusão, apresenta-se a figura do IE, denominação não ingênua -- que carrega sentidos provenientes da esfera do discurso em que atua, a

Cad. Trad., Florianópolis, v. 41, $\mathrm{n}^{0}$ esp. 2, p. 107-127, ago/dez, 2021. 112 
esfera acadêmica. Nesse contexto, então, todo enunciado passa a referir-se à relação de pelo menos três sujeitos - professor, intérprete e aluno surdo - sujeitos constituídos cada um por uma realidade histórica, social e cultural diferente. Nele circulam línguas constituídas em espaços de produção cultural diferentes, com o IE inserido na fronteira entre a maioria linguística "dita colonizadora" (ouvintes) e a minoria linguística (surdos) que luta pelo lugar de sua língua na sociedade (Lodi 409-424, 49-63).

É importante salientar que a interpretação educacional carrega consigo algumas características, o IE tem a responsabilidade de proporcionar ao aluno surdo a compreensão e apreensão dos conteúdos de forma constante já que o acompanha ao longo do curso e pode perceber consequências de suas interpretações anteriores na construção de sentidos que são retomados nas aulas, diferentemente do intérprete de conferências, por exemplo, que passa pelos temas interpretados de forma efêmera já que após seu trabalho não acompanha necessariamente o sujeito surdo e tem um compromisso menos indelével com as consequências de sua interpretação (Nogueira; Santos).

Não obstante, o IE tem a possibilidade de, durante a interpretação, interagir verbalmente com professores e alunos. Ressaltase que na esfera acadêmica há a predominância da interpretação simultânea e em primeira pessoa, com indicação pronominal, ou seja, a apontação (com a mão ou com o direcionamento do olhar) com o intuito de indicar quem está falando, ou em situações onde há troca de turno de fala. Nesse contexto, o intérprete é interlocutor e também locutor. É a interação que organiza as interlocuções na atividade - o intérprete, o eu, que é sempre respondente ao outro. Quando o intérprete toma a palavra, ou melhor dizendo, enuncia, está respondendo ao aluno surdo e, ao mesmo tempo, à produção de sentido do professor ou de outro interlocutor, sua fala sempre pressupõe o outro na construção de sentidos e na elaboração conceitual em sala de aula.

Cad. Trad., Florianópolis, v. 41, $\mathbf{n}^{0}$ esp. 2, p. 107-127, ago/dez, 2021. 113 


\section{Metodologia}

A etnografia, como procedimento de pesquisa adotado na educação, não requer definição inicial de um modelo teórico acabado que delimite o processo de observação. Um desdobramento da pesquisa etnográfica estabelece-se na pesquisa participante, modalidade que possibilita formas de interação entre o pesquisador e os sujeitos. (Ezpeleta e Rockwell). É nessa categoria, bastante utilizada em pesquisas no contexto educacional que localizamos esta pesquisa, pelo motivo de que a pesquisadora é uma das intérpretes do curso, participante ativa das interações nesse contexto.

Bakhtin, a partir de sua teoria da linguagem nos possibilita compreender a pesquisa em ciências humanas numa perspectiva dialógica, assumindo o valor da compreensão construída a partir dos textos signícos criados pelo homem, e do caráter interpretativo dos sentidos construídos na relação dos textos com os contextos (Freitas). Na perspectiva enunciativa discursiva "o objeto das ciências humanas é o ser expressivo e falante" (Bakhtin "Notas sobre literatura..." 59), o homem como produtor de textos e vozes que interagem dialogicamente com seus interlocutores e consigo mesmo.

Os participantes foram dois intérpretes de língua brasileira de sinais (Libras) (a primeira autora e outro profissional convidado); um aluno surdo matriculado no curso de pós-graduação lato sensu; professores do referido curso e demais alunos ouvintes. Os intérpretes de Libras no contexto estudado, se revezavam de 20 em 20 minutos, se posicionando um de frente para o outro, com o intérprete do turno sentado ao lado do professor e o intérprete de apoio sentado ao lado do aluno.

Os dados foram coletados através de vídeo gravação das interpretações (da língua portuguesa para Libras) das aulas, em uma universidade, local da pesquisa. Foram utilizadas duas filmadoras e tripés; um diário de campo para registrar ocorrências não documentadas pelo vídeo. As filmadoras foram posicionadas com o objetivo de capturar imagens em duas perspectivas: uma com foco no IE e professor e outra com foco nos alunos conforme figura 1.

Cad. Trad., Florianópolis, v. 41, $\mathrm{n}^{0}$ esp. 2, p. 107-127, ago/dez, 2021. 114 
Figura 1 - Imagens da sala de aula
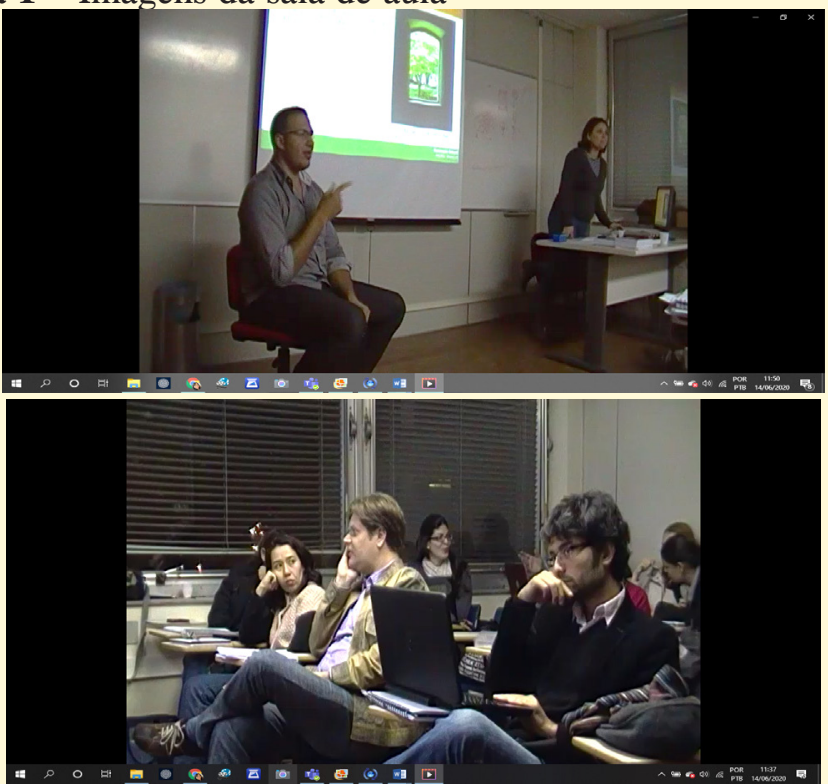

Fonte: As autoras

O contexto foi um curso de especialização em Sustentabilidade nas Edificações com duração de três semestres. Os professores, majoritariamente arquitetos e engenheiros civis, são profissionais e especialistas reconhecidos, sem histórico de docência necessariamente. Os alunos, cerca de 12 , em sua maioria arquitetos, tinham trajetória profissional de grande experiência, e poucos eram recém-formados. O aluno surdo cursou arquitetura como formação inicial, era na ocasião funcionário de empresa de projetos de arquitetura estrutural. Os intérpretes, ambos tinham experiência de interpretação na esfera educacional e em outras esferas de atuação (conferências, eventos políticos e atendimentos específicos).

$\mathrm{Na}$ esfera acadêmica circulam diferentes gêneros do discurso, esta análise considera o contexto da pós-graduação lato sensu, que 
para nós tem características relativamente estáveis passíveis de serem observadas e relacionadas com a atuação dos IEs.

\section{No contexto da pós-graduação}

Para Bakhtin todo estilo está indissoluvelmente ligado ao enunciado e às formas típicas de enunciados, ou seja, aos gêneros do discurso situados nos diferentes campos da comunicação discursiva (Bakhtin). No entanto, nem todos os gêneros são facilmente delimitados e descritos, pois na construção dos enunciados outros aspectos também importam, como por exemplo a individualidade dos falantes. Nos estudos dos gêneros o estilo individual não faz parte do plano do enunciado, a considerar que mesmo o estilo individual é afetado pelas coerções de cada gênero do discurso, nas diferentes esferas da atividade humana.

Os gêneros do discurso organizam o nosso discurso quase da mesma forma que organizam as formas gramaticais (sintáticas). Nós aprendemos a mudar o nosso discurso em formas de gênero e, quando ouvimos o discurso alheio, já adivinhamos o seu gênero pelas primeiras palavras, adivinhamos certo volume (isto é, uma extensão aproximada do conjunto do discurso), uma determinada construção composicional, prevemos o fim, isto é, desde o início temos a sensação do conjunto do discurso que, em seguida, apenas se diferencia no processo da fala. (BAKHTIN 39).

A questão do gênero do discurso nos interessa já que é também pelas mãos do intérprete, que os enunciados circulantes em sala de aula são mobilizados, que os alunos surdos têm acesso ao gênero do discurso e suas coerções. A atuação dos IEs em diferentes gêneros do discurso demanda diferentes posicionamentos axiológicos e distintas tomadas de decisão tradutórias frente aos enunciados a serem interpretados. Assim, organizamos nossas análises consi-

Cad. Trad., Florianópolis, v. 41, $\mathrm{n}^{0}$ esp. 2, p. 107-127, ago/dez, 2021. 116 
derando: i) a valoração dos enunciados pelos IEs; e ii) o estilo de linguagem e as estratégias de interpretação.

$\mathrm{Na}$ educação circulam diversos tipos de interações entre sujeitos concretos, interações vivas estabelecidas pelos papeis sociais que os sujeitos assumem, como: gestor, professor, aluno, etc. Dentre os discursos que circulam na esfera acadêmica, o gênero aula teórica expositiva com apresentação de slides é bastante característico da pós-graduação. No entanto, além desses outros formatos recorrentes foram observados: análise de projetos, desenho de solução arquitetônica, trabalho/ pesquisa em grupo, estudo de norma técnica, navegação em plataforma digital de certificação, apresentação de seminário, momento de orientação de monografia, preenchimento de formulário técnico, discussões com os colegas, conversas paralelas, etc. Cada um desses gêneros se organiza de forma distinta e representam diferentes desafios para atuação dos IEs.

Na pós-graduação, muitas aulas são bastante dialogadas e em diversas situações as discussões acontecem com falas simultâneas e, mesmo nas aulas não dialogadas, ocorre interação frequente entre alunos e professores durante a exposição de conteúdos pelo professor. Durante a pesquisa, ainda que os participantes estivessem conscientes que a aula seria interpretada e que houvesse um acordo na turma para que não falassem todos ao mesmo tempo, para que as discussões fossem mais organizadas, as interações, em geral, seguiam naturalmente sem a lembrança da presença e da atuação do intérprete.

Nesse ponto, focalizando as relações de hierarquia e poder em sala de aula, podemos afirmar que o professor é figura de autoridade. O professor normalmente detém o saber e o gerenciamento dos conteúdos e das atividades em sala. São professores do curso, titulados (mestres e doutores) com experiência destacada. Entretanto, em nível de pós-graduação, as falas dos alunos também podem ganhar espaço privilegiado, considerando que a maioria atua profissionalmente, com experiência, possuindo também conhecimento de valor para as interações. As posições hierárquicas se alternam, e constituem interessante elemento para análise nes-

Cad. Trad., Florianópolis, v. 41, n $^{0}$ esp. 2, p. 107-127, ago/dez, 2021. 117 
se contexto, configurando aulas mais dialogadas, característica desse nível de ensino.

No recorte escolhido para este artigo caracterizamos como aula teórica expositiva com apresentação de slides, a professora explica que a percepção de cor, a partir de um objeto iluminado, se forma artificialmente se distanciando da percepção real proporcionada pela "iluminação natural".

A professora apresenta nos slides um exemplo com duas imagens de uma mesma fruta, fotografias tomadas com iluminação natural e com uma iluminação artificial ruim. Apresenta também um quadro de classificação de luminância $\mathrm{x}$ reprodução de cor, e diferentes aplicações em diferentes ambientes. Imediatamente a professora é interrompida por um aluno ouvinte, que parece discordar dela, perguntando em tom de discordância: Mas existem ainda lâmpadas que têm o IRC $C^{2}$ tão ruim assim [como das imagens]. A professora responde com tranquilidade: Eu acho que exista sim, eu não trabalho muito com iluminação artificial, então eu sei pouco do que tem no mercado, mas eu acho que deve existir sim né”. O aluno responde com tom provocativo: Você imagina um lugar que você precisa decifrar as cores lá das lixeiras do lixo reciclável, se tão ruim é o índice de reprodução de cores, você não enxerga nada. Todos alunos dão risada e a professora responde fazendo graça: Por isso que vem escrito [escrito o tipo de lixo nas lixeiras]. Os alunos seguem debatendo o assunto com a professora, apresentando diferentes percepções. Esse tipo de interação ocorre com frequência em diferentes aulas, compondo o modus operandi do curso.

Chamamos atenção para a atuação do intérprete nesse recorte, antes mesmo do aluno ouvinte fazer a pergunta provocativa, ainda durante a interpretação da explicação da professora o intérprete aponta para ele e copia sua gesticulação "mão no queixo" - sugerindo que o aluno surdo perceba a expressão facial de discordância de dele que aparenta se preparar para interpelar a professora segundos depois acontece a pergunta, o intérprete termina de in-

${ }^{2}$ IRC: Índice de reprodução de cor para projetos de iluminação predial.

Cad. Trad., Florianópolis, v. 41, $\mathrm{n}^{0}$ esp. 2, p. 107-127, ago/dez, 2021. 118 
terpretar rapidamente a fala da professora, para de interpretar por segundos pois o aluno surdo se vira para observar o colega que discorda da professora. O intérprete observa a pergunta do aluno ouvinte, utiliza a memória de curto prazo e a interpreta de forma consecutiva assim que o aluno surdo volta o direcionamento do olhar para ele: ELE [SINAL-DO-ALUNO] PERGUNTAR: ESPERA, TER LÂMPADAS TER I-R-C PESSIMO TER $?^{3}$ Seguindo com a interpretação simultânea da fala da professora: ELA AVISAR - TER, EU NÃO COSTUME TRABALHAR MUITO IA [iluminação artificial]. Aponta para o aluno ouvinte: ELE SINALDO-ALUNO DIZ - IMAGINAR LUGAR TRABALHO TENTAR IDENTIFICAR CORES LIXO LUZ ARTIFICIAL POIS-É? Aponta para a professora "TER RÓTULO O-R-G-A-N-I-C-O R-E-C-I-C-L-A-V-E-L [faz movimento negativo com a cabeça expressão sarcástica]. Aponta para a turma: RISADAS... O aluno surdo também ri com a turma.

Os IEs seguem interpretando o debate dos colegas que engrossam o debate. Esse é um recorte que sugere a atenção do IE para a interação de toda a turma incluindo na sua interpretação diferentes aspectos para além dos enunciados verbais, no uso de referenciais corretos e de entonações.

Em consonância com os estudos de gêneros, no que diz respeito ao endereçamento dos enunciados, temos a situação de um aluno surdo que se posiciona e participa efetivamente das aulas, mas para isso, precisa ser munido de todas as informações circulantes na sala.

Observando os vídeos, de diferentes momentos desta aula e de outras, percebemos que os IEs se esforçam para não privilegiar uma fala ou outra, atuando em dupla, interpretam quase todo o tempo todos os enunciados, incluindo perguntas, concordâncias e discordâncias com a explanação dos professores, assim como a interpretação da gesticulação ou da expressão facial dos alunos em torno do tema discutido, incluindo conversas paralelas entre alunos. Mesmo que a disposição da sala seja tradicional, professor e

${ }^{3}$ Transcrição por uso de glosas (Mccleary, Viotti e Leite).

Cad. Trad., Florianópolis, v. 41, $\mathbf{n}^{0}$ esp. 2, p. 107-127, ago/dez, 2021. 119 
intérprete à frente e carteiras dispostas em fileira mais ou menos organizadas, as relações entre os interlocutores acontecem de forma menos tradicional.

Julgamos necessário fazer um paralelo aqui com outro gênero do discurso. Considerando esse mesmo conteúdo apresentado em uma conferência acadêmica ou em uma palestra de treinamento profissional, que constituem gêneros do discurso distintos, os enunciados dos participantes não seriam considerados na interpretação da mesma forma que foram incorporados na dinâmica aqui apresentada. Cada gênero do discurso, para além do conteúdo e estilo composicional, é fortemente caracterizado pela relação entre os falantes.

\begin{abstract}
Quanto mais dominamos os gêneros, maior é a desenvoltura com que os empregamos e mais plena e nitidamente descobrimos neles a nossa individualidade (onde isso é possível e necessário), refletimos de modo mais flexível e sutil a situação singular da comunicação - em suma, tanto mais plena é a forma com que realizamos o nosso livre e projeto de discurso. (Bakhtin 41)
\end{abstract}

Os aspectos observados nos levantam a proposição de que o gênero do discurso implica e é mandatório no fazer do IE. Nos vídeos analisados observamos um esforço em interpretar todos os enunciados como composição de um projeto discursivo, mesmo que fossem falas que aconteciam concomitantemente à apresentação oral do professor. Observamos nos vídeos que em vários momentos o IE pretere da explicação do(a) professor(a) para interpretar uma observação ou experiência prática trazida pelos alunos. Quando o intérprete do turno não consegue interpretar as duas falas, o intérprete de apoio faz a vez do interpelador e assume automaticamente a interpretação, ou vice e versa, o intérprete que está à frente assume o enunciado do aluno que interpela e é o intérprete de apoio que assegura a continuidade da interpretação da explicação ou resposta do(a) professor(a).

Cad. Trad., Florianópolis, v. 41, $\mathbf{n}^{0}$ esp. 2, p. 107-127, ago/dez, 2021.120 
Nessa situação, a sobreposição de enunciados é possível devido à característica de modalidade da língua de sinais - gestual-visual . Essa condição permite a simultaneidade entre dois interlocutores, na situação de interpretação simultânea a intermodalidade permite a sobreposição entre língua vocal-auditiva e língua gestual-visual sem comprometer a dinâmica de interação entre as pessoas envolvidas (Rodrigues).

Podemos dizer que esse gerenciamento feito pelos intérpretes está diretamente ligado às coerções do gênero discursivo em que atuam e da realidade material das línguas de trabalho, e sobre esse aspecto é importante dizer que a dupla de intérpretes relata não ter combinado essa dinâmica na atuação. Conforme Albres e Rodrigues, "as escolhas e tomadas de decisão que caracterizam os processos tradutórios e interpretativos são feitas com base em características contextuais, políticas e ideológicas" (23).

Podemos inferir, então, que essa forma de atuação emerge naturalmente da situação de interpretação nesse determinado gênero do discurso. Os IEs parecem considerar importante dar visibilidade a todos os enunciados (professores e colegas) porque no debate diferentes experiências emergem, e para eles, nos parece, todas merecem destaque. Essa valoração dos intérpretes, mesmo não sendo estabelecida explicitamente, configura-se como posicionamento axiológico, a partir do reconhecimento da sala de aula como um espaço formativo - os IEs parecem valorar todas as experiências trazidas como meritórias e pertinentes à formação do As.

Um segundo ponto a ser destacado é o estilo de linguagem e as estratégias de interpretação adotadas pelos intérpretes nesse gênero do discurso, aula de pós-graduação. Observamos que os IEs retomam com recorrência algum ponto das aulas anteriores (Santiago, 2013), característica da interpretação educacional. Porém, em raras situações fazem explicações do conteúdo, direcionando o As para a interação com o professor ou colegas, considerando a forma de interação nas aulas, os interlocutores e a quantidade de conteúdos teóricos e técnicos, o intérprete não teria condições para fazer muitas explicitações ou paráfrases.

Cad. Trad., Florianópolis, v. 41, $\mathrm{n}^{0}$ esp. 2, p. 107-127, ago/dez, 2021. 121 
Em se tratando da esfera educacional e da tríade professor, intérprete e alunos, as interações também se organizam em função do nível de ensino e da relação de hierarquia e poder entre os interlocutores. Na aula o professor é a autoridade perante os alunos, ele tem um certo controle do andamento da aula. Contudo, em alguns momentos, o IE também pode se destacar nessa relação, especialmente para os alunos surdos, isso porque o IE é também detentor do saber e, por vezes, faz explicações paralelas e esclarecimentos dos discursos circulantes em sala de aula, favorecendo a aprendizagem dos alunos surdos. Diferentes pesquisas sobre a atuação do IE no EF indicam esses aspectos. (Lacerda; Lacerda e Lodi; Lodi 49-63; Santos; Menezes-Sales; Santos e Lacerda; Menezes e Lacerda).

$\mathrm{Na}$ aula de pós-graduação ao observar as relações de hierarquias, o IE não tem o muito poder, ele não é autoridade no assunto, não é especialista, professores e alunos têm mais valor nessa relação, e nesse sentido, o tipo de linguagem e as estratégias de interpretação frequentemente se atêm a transmitir literalmente as informações que circulam em sala, com uso de siglas, decalques e estrangeirismos. A literalidade, nesse caso, não deve ser confundida com tradução palavra por palavra, já que mesmo que na tradução/interpretação no contexto acadêmico possa ser observada a literalidade - predominância de termos da língua de partida os enunciados são organizados respeitando a relação sintática e semântica da língua de tradução (Santiago 35-55).

A partir do exposto, consideramos que tanto a linguagem importa, quanto os aspectos dialógicos que emergem das relações entre os participantes das interações discursivas em cada gênero do discurso.

\section{Considerações finais}

Hoje, os Estudos da Tradução e da Interpretação de Línguas de Sinais configuram um campo interdisciplinar que permite a congruência de diferentes abordagens teóricas que lançam olhar sobre

Cad. Trad., Florianópolis, v. 41, $\mathrm{n}^{0}$ esp. 2, p. 107-127, ago/dez, 2021. 122 
diferentes esferas e gêneros discursivos em que o Tradutor e Intérprete de língua de sinais atua.

A interpretação na pós-graduação, exige do IE, não o domínio dos conteúdos, mas a necessidade de conhecer o tipo de linguagem e terminologias, em português e também em língua estrangeira (inglês). Nesse contexto, as estratégias de interpretação passam a operar sobre o ponto de vista de mediar os conteúdos e de assegurar que a linguagem técnica específica do campo de conhecimento seja explicitada na interpretação.

Consideramos que seu fazer, está embebido das concepções sobre a esfera educacional e sobre o contexto acadêmico especificamente. Observamos que IEs trabalham para dar visibilidade a todos os enunciados circulantes, os valoram e os colocam em circulação a partir das decisões de tradução, consideram todas as experiências trazidas na sala de aula como meritórias e pertinentes à formação do aluno surdo. Essa valoração configura-se como posicionamento axiológico a partir do reconhecimento da sala de aula como um espaço formativo.

Consideramos também, que a atuação dos IEs é regida pelas coerções do gênero e, portanto, as decisões tradutórias, estilo de linguagem, modalidades de interpretação e formas de interação dizem respeito ao contexto específico em que atua, e sobre as estratégias apresentadas, essas não poderiam ser mimeticamente replicadas em outra situação de interpretação, ainda que na esfera educacional ou em outro espaço da esfera acadêmica. Ressaltamos ainda que, o profissional TILS tem dentre as suas tarefas o reconhecimento do gênero do discurso em que atua e a responsabilidade de operar sobre esse gênero.

Cad. Trad., Florianópolis, v. 41, $\mathbf{n}^{0}$ esp. 2, p. 107-127, ago/dez, 2021.123 


\section{Referências}

Albres, Neiva de Aquino e Santiago, Vânia de Aquino Albres. A construção de metáforas sobre intérpretes de língua de sinais: polifonia em questão. Translatio UFRGS: 2018, p. 6-32. Disponível em: < https://seer.ufrgs.br/translatio/article/ viewFile/80694/48556>.

Albres, Neiva de Aquino e Rodrigues, Carlos Henrique. As funções do intérprete educacional: entre práticas sociais e políticas educacionais. Bakhtiniana, São Paulo, 13 (3): 16-41, Set./Dez. 2018. Disponível em: < https://www.scielo.br/ $\mathrm{pdf} / \mathrm{bak} / \mathrm{v} 13 \mathrm{n} 3 / 2176-4573-\mathrm{bak}-13-03-0015 . \mathrm{pdf}>$.

Bakhtin, Mikhail. Os gêneros do discurso. In: Bakhtin, Mikhail. Os gêneros do discurso. Paulo Bezerra (Organização, tradução, Posfácio e Notas); Notas da edição russa: Seguei Botcharov. São Paulo: Editora 34, 2016 [1979].

Bakhtin, Mikhail. Por uma metodologia das ciências humanas. In: Bakhtin, Mikhail. Notas sobre literatura, cultura e ciências humanas. Org. Trad. Posf. e Notas Paulo Bezerra. São Paulo: Editora 34, 2017. [1930-40]

Brait, Beth. Bakhtin e a natureza constitutivamente dialógica da linguagem. In: BRAIT, Beth. Bakhtin: dialogismo e construção do sentido. Campinas, SP: editora da Unicamp, 2005.

Ezpeleta, Justa e Rockwell, Elsie. Pesquisa Participante. São Paulo: Cortez autores associados, $2^{\text {a }}$ edição, 1989.

Freitas, Maria Teresa de. A perspectiva sócio-histórica: uma visão humana da construção do conhecimento In: Freitas, Maria Teresa de; Souza, Solange Jobim e; Kramer, Sônia. Ciências humanas e pesquisa: leituras de Mikhail Bakhtin. 2.ed. São Paulo: Cortez, 2007.

Lacerda, Cristina Broglia Feitosa de. A prática pedagógica mediada (também) pela língua de sinais: trabalhando com sujeitos surdos. Cad. CEDES [online]. 2000, v. 20, n. 50, pp. 70-83. Disponível em: < https://www.scielo.br/pdf/ ccedes/v20n50/a06v2050.pdf $>$. 
Lacerda, Cristina Broglia Feitosa de. O intérprete educacional de língua de sinais no ensino fundamental: refletindo sobre limites e possibilidades. In: Lodi, Ana Claudia Balieiro (et al.) Letramento e minorias. $2^{\mathrm{a}}$ edição. Mediação, Porto Alegres: 2003.

Lacerda, Cristina Broglia Feitosa de. Intérprete de libras em atuação na educação infantil e no ensino fundamental. Porto Alegre: Editoria Mediação, 2009.

Lodi, Ana Claudia Balieiro. Plurilingüismo e surdez: uma leitura bakhtiniana da história da educação dos surdos. Educação e Pesquisa, São Paulo, v. 31, n. 3, p. 409-424, set./dez. 2005. Disponível em: < https://www.scielo.br/pdf/ep/v31n3/ a06v31n3.pdf $>$.

Lodi, Ana Claudia Balieiro. Educação bilíngue para surdos e inclusão segundo a Política Nacional de Educação Especial e o Decreto n. 5.626/05. Educação e Pesquisa. São Paulo, v. 39, n. 1, p. 49-63, jan./mar. 2013. Disponível em: $<$ https://www.scielo.br/pdf/ep/v39n1/v39n1a04>.

Mccleary, Leland; Viotti, Evani e Leite, Tarcísio de Arantes. Descrição das línguas sinalizadas: a questão da transcrição dos dados. Alfa, São Paulo, 54 (1): 265-289, 2010. Disponível em: < https://periodicos.fclar.unesp.br/alfa/article/ view/2880>.

Mendes, Regina Maria Russiano. Afinal: intérprete de língua de sinais, intérprete educacional, professor intérprete ou auxiliar? o trabalho de intérpretes na lógica inclusiva. In: Albres, Neiva de Aquino e Santiago, Vânia de Aquino Albres (orgs.). Libras em estudo: tradução-interpretação. São Paulo: FENEIS, 2012. Disponível em: <https://libras.ufsc.br/wp-content/uploads/2019/09/2012-04ALBRES-e-SANTIAGO_LIBRAS_trad_int.pdf $>$.

Nascimento, Marcus Vinícius Batista. Interpretação da língua brasileira de sinais a partir do gênero jornalístico televisivo: elementos verbo-visuais na produção de sentidos. Dissertação (Mestrado) - Programa de Estudos Pós-Graduados em Lingüística Aplicada e Estudos da Linguagem - Pontifícia Universidade Católica de São Paulo, 2011. Disponível em: < https://sapientia.pucsp.br/handle/ handle/13551>.

Nogueira, Tiago Coimbra. Intérpretes de libras-português no contexto de conferência: uma descrição do trabalho em equipe e as formas de apoio na 
cabine. 2016. Dissertação (Mestrado) - Universidade Federal de Santa Catarina, Centro de Comunicação e Expressão, Programa de Pós-Graduação em Estudos da Tradução, Florianópolis. Disponível em: <http://www.bu.ufsc.br/teses/ PGET0299-D.pdf > .

Rodrigues, Carlos Henrique. Interpretação simultânea intermodal: sobreposição, Performance corporal-visual e direcionalidade inversa. Revista da Anpoll v. 1, $\mathrm{n}^{\mathrm{o}}$ 44, p. 111-129, Florianópolis, Jan./Abr. 2018. Disponível em: <https:// revistadaanpoll.emnuvens.com.br/revista/article/view/1146/940>.

Santiago, Vânia de Aquino Albres. Português e Libras em diálogo: os procedimentos de tradução e o campo do sentido. In: Albres, Neiva de Aquino; Santiago, Vânia de Aquino Albres. (Org.). Libras em Estudo: Tradução/ Interpretação. 1ed.São Paulo: Feneis, 2012, v. 1, p. 35-55. Disponível em: $<$ https://libras.ufsc.br/wp-content/uploads/2019/09/2012-04-ALBRES-eSANTIAGO_LIBRAS_-trad_int.pdf $>$.

Santiago, Vânia de Aquino Albres. Atuação de intérpretes de língua de sinais na pós-graduação lato sensu: estratégias adotadas no processo dialógico. Dissertação (Mestrado) Universidade federal de São Carlos - UFSCar - Programa de Pósgraduação e m Educação Especial. São Carlos: UFSCar, 2013. Disponível em: $<$ https://repositorio.ufscar.br/handle/ufscar/3119? show $=$ full $>$.

Santiago, Vânia de Aquino Albres e Lacerda, Cristina Broglia de Feitosa. O intérprete de libras educacional: o processo dialógico e as estratégias de mediação no contexto da pós-graduação. Revista Belas Infiéis, v. 5, p. 165-182, 2016. Disponível em: <https://periodicos.unb.br/index.php/belasinfieis/article/ view/11375/10012>.

Santos, Lara Ferreira dos e Lacerda, Cristina Broglia Feitosa de. Atuação do intérprete educacional: parceria com professores e autoria. Cadernos de Tradução, v. 35, p. 505-533, 2015. Disponível em: <https://periodicos.ufsc.br/index.php/ traducao/article/view/2175-7968.2015v35nesp2p505/30723>.

Santos, Kátia Andréia Souza dos. O intérprete de Libras no contexto de conferência: reflexões sobre sua atuação, 2016. Dissertação (Mestrado). Universidade Federal de São Carlos, UFSCAR, Brasil. Programa de Pósgraduação em Educação Especial, 2016. Disponível em: < https://repositorio. ufscar.br/handle/ufscar $/ 8322$ ?show $=$ full $>$.

Cad. Trad., Florianópolis, v. 41, $\mathbf{n}^{0}$ esp. 2, p. 107-127, ago/dez, 2021.126 
Sobral, Adail Ubirajara. Dizer o mesmo aos outros: ensaios sobre tradução. São Paulo: Special Book Service Livraria, 2008.

Vânia de Aquino Albres Santiago. E-mail: vania.santiago10@yahoo.com.br. https://orcid.org/0000-0002-3533-9835.

Cristina Broglia Feitosa de Lacerda. E-mail: cristinalacerda@uol.com.br. https:// orcid.org/0000-0002-3250-1374.

Cad. Trad., Florianópolis, v. 41, $\mathbf{n}^{0}$ esp. 2, p. 107-127, ago/dez, 2021. 127 